$\begin{array}{cc}\text { ACADEMIA ROMÂNĂ } & \text { Rev. Roum. Chim., } \\ \text { Revue Roumaine de Chimie } & \text { 2019, 64(5), 409-413 } \\ \text { http://web.icf.ro/rrch/ } & \text { Doi: 10.33224/rrch.2019.64.5.04 }\end{array}$

\title{
RAPID GREEN BIOSYNTHESIS AND CHARACTERIZATION OF SILVER NANOPARTICLES USING GLUCOSE AS A GREEN ROUTE
}

\author{
Sajjad SEDAGHAT, ${ }^{\mathrm{a}^{*}}$ Elham ARSHADI, ${ }^{\mathrm{a}}$ Alireza $\mathrm{NAFAR}^{\mathrm{a}, \mathrm{b}}$ and Reza DABBAGH ${ }^{\mathrm{b}}$ \\ ${ }^{\mathrm{a}}$ Department of Chemistry, College of Science, Shahr-e-Qods Branch, Islamic Azad University, Shahr-e-Qods, Iran \\ ${ }^{\mathrm{b}}$ Nuclear Sciences \& Technology Research Institue, Nuclear Fuel Cycle Research School (NFCRS)
}

Received December 12, 2017

The biosynthesis of nanoparticles is an important field in nanotechnology which can be developed as: eco friendly, rapid and green route compared to traditional methods. In this work, green biosynthesis of silver nanoparticles (Ag-NPs) using glucose solution as a reducing and capping agent is carried out at ambient temperature. The synthesized Ag-NPs were characterized by UV-Vis, FTIR, XRD and TEM analysis. The UV-Vis spectral studies confirmed the surface plasmon resonance of biosynthesized silver nanoparticles. TEM results showed that mean diameter of silver nanoparticles were about $11 \mathrm{~nm}$.
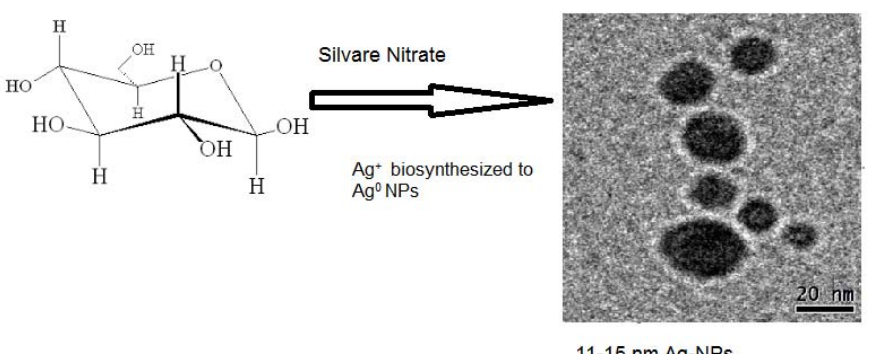

$11-15 \mathrm{~nm}$ Ag-NPs

\section{INTRODUCTION}

In recent years, nanotechnology is an escalating field of modern research involving in synthesis design, characterization, production and application of structures, devices and systems by controlling shape and size at the nanometer scale. ${ }^{1}$ Physical methods for the synthesizing of nanoparticles are costly and cumbersome for the large scale production. Otherwise, chemical methods use toxic chemicals, which are hazardous for the environment and often result in the adsorption of toxic chemicals on to the surface of synthesized silver nanoparticles, making them unsuitable for biomedical uses. ${ }^{2-4}$ Green method use naturally precursors such as vitamins, sugars, microorganisms and plant extracts as reductant agents are more eco-friendly and effective. ${ }^{5}$ Biological synthesis methods, using biomolecules present in plant extracts, because of the good capacity in reduction of metal ions to nanoparticles and being natural good capping agents in the controlling of particle size, is better process than hazardous chemicals and costly physical methods. $^{6-9}$ Therefore, this method involves biocompatible materials which are non-toxic solvent, environmental friendly, low energy and time expenditure for biosynthesis of silver nanoparticles. ${ }^{10} \mathrm{~A}$ number of biomolecules in extracts have been shown to successfully act as reducing agents in the green synthesis of AgNPs. For example, the green synthesis of Ag-NPs by using pennyroyal water extract were reported. ${ }^{11}$ In another study, AgNPs were synthesized by utilizing various monosaccharides as reductant; with employing the household microwave method described earlier. ${ }^{12}$ The biosynthesis of silver nanoparticles using fruit extract of Malus Domestica was furthermore reported and the average particle size was found to be $20 \mathrm{~nm} .{ }^{13}$ Also biosynthesis of silver nanoparticles using water extract of Satureja hortensis $L$ was successfully

\footnotetext{
*Corresponding author: sajjadsedaghat@yahoo.com
} 
carried out. ${ }^{14}$ Previously, synthesis and characterization of ployethylene glycol mediated silver nanoparticles by the green method were evaluated. ${ }^{15}$ In this research, we have reported the glucose solution which was used for rapid, simple and stabilizer biosynthesis of silver nanoparticles at room temperature. Different studies showed that the extract, rich of biomolecules, can be a good choice for bio-reduction processes. Furthermore, green synthesized Ag-NPs were characterized by UV-Vis, FT-IR, XRD and TEM techniques.

\section{MATERIALS AND METHODS}

\section{Materials}

Silver nitrate $\left(\mathrm{AgNO}_{3}, 99 \%\right)$, glucose $\left(\mathrm{C}_{6} \mathrm{H}_{12} \mathrm{O}_{6}\right)$ were provided from Merck (Germany). The chemicals purchased a high purity grade. All the sample were used without any further treatment. All solution were freshly prepared each time, using doubly distilled water.

\section{Synthesis of silver nanoparticles}

For the synthesis of Ag-NPs, $2.5 \mathrm{~mL}$ of $0.01 \mathrm{M}$ $\mathrm{AgNO}_{3}$ solution was used, and a solution containing $5 \%(\mathrm{~W} / \mathrm{W})$ of glucose in water was prepared and used as reducing agent. Then two solutions were mixed drop by drop while the mixture was stirring. The color changed from yellow to dark brown at room temperature, and
Ag-NPs were gradually obtained during the reaction.

\section{Characterization of silver nanoparticles}

The UV-Visible spectra were recorded between 300-800 nm with a (UV, Bio-TEK) UV-Visible spectrophotometer. The Fourier transform infrared (FTIR) spectra of silver nanoparticles were performed with the use of FTIR (Perkin-Elmer, Spectrum100, Germany) spectrophotometer with $\mathrm{KBr}$ pellet in the range of $4000-400$. The X-ray diffraction (XRD, Inel, EQUINX 3000) is one of the crucial ways for the structure characterization of the crystalline material. The transmission electron microscopy (TEM) observations were carried out using (TEM, Zeiss, EM 10 C-100KV) electron microscope and it studies the characterization of the nanoparticles surface morphology and measures the size.

\section{RESULTS AND DISCUSSION}

\section{UV-Vis Spectrophotometry}

Figure 1 indicates the UV-Vis spectra recorded from aqueous solution of silver nitrate with glucose solution. UV-Vis absorption measurements for silver nanoparticles are carried out in the range of $328-800 \mathrm{~nm}$. In this research, the UV-Vis spectra of silver nanoparticles synthesized displayed a peak around $425 \mathrm{~nm}$ due to the formation of AgNPs.

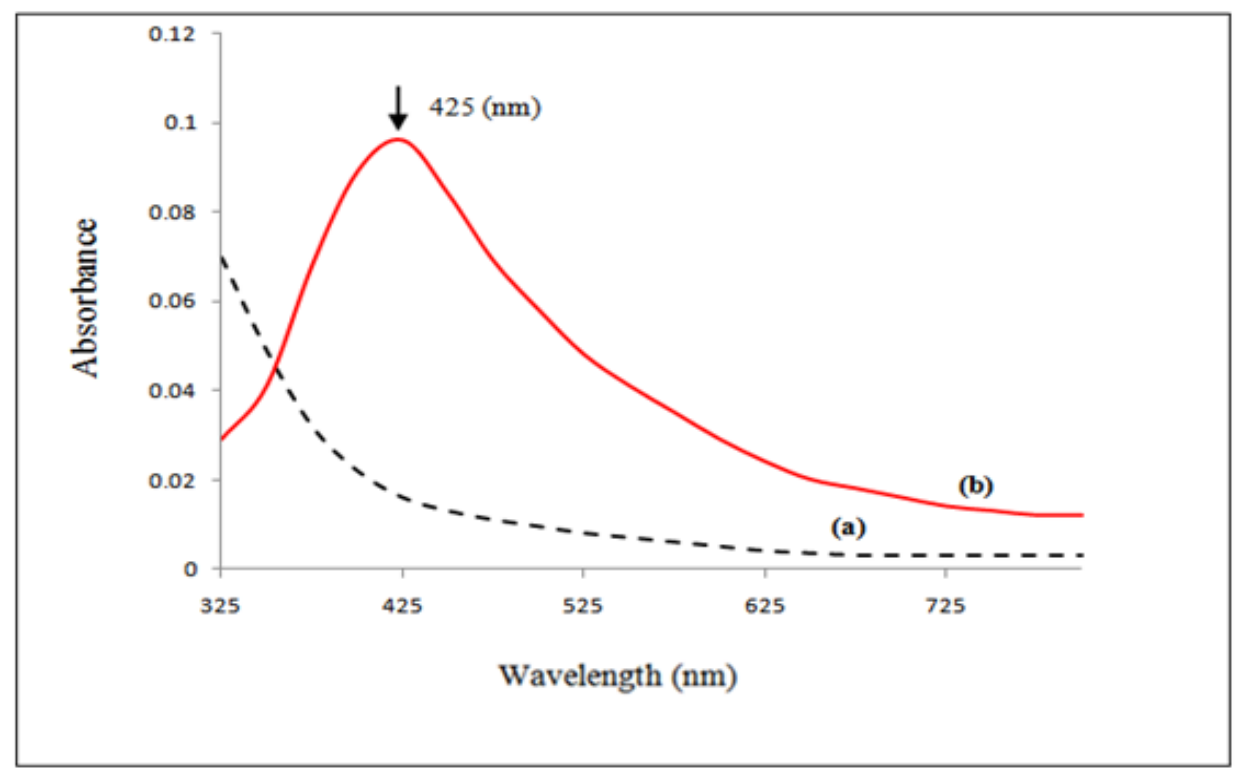

Fig. 1 - UV-Vis absorption spectra of (a) glucose solution and (b) AgNPs dispersed in water. 


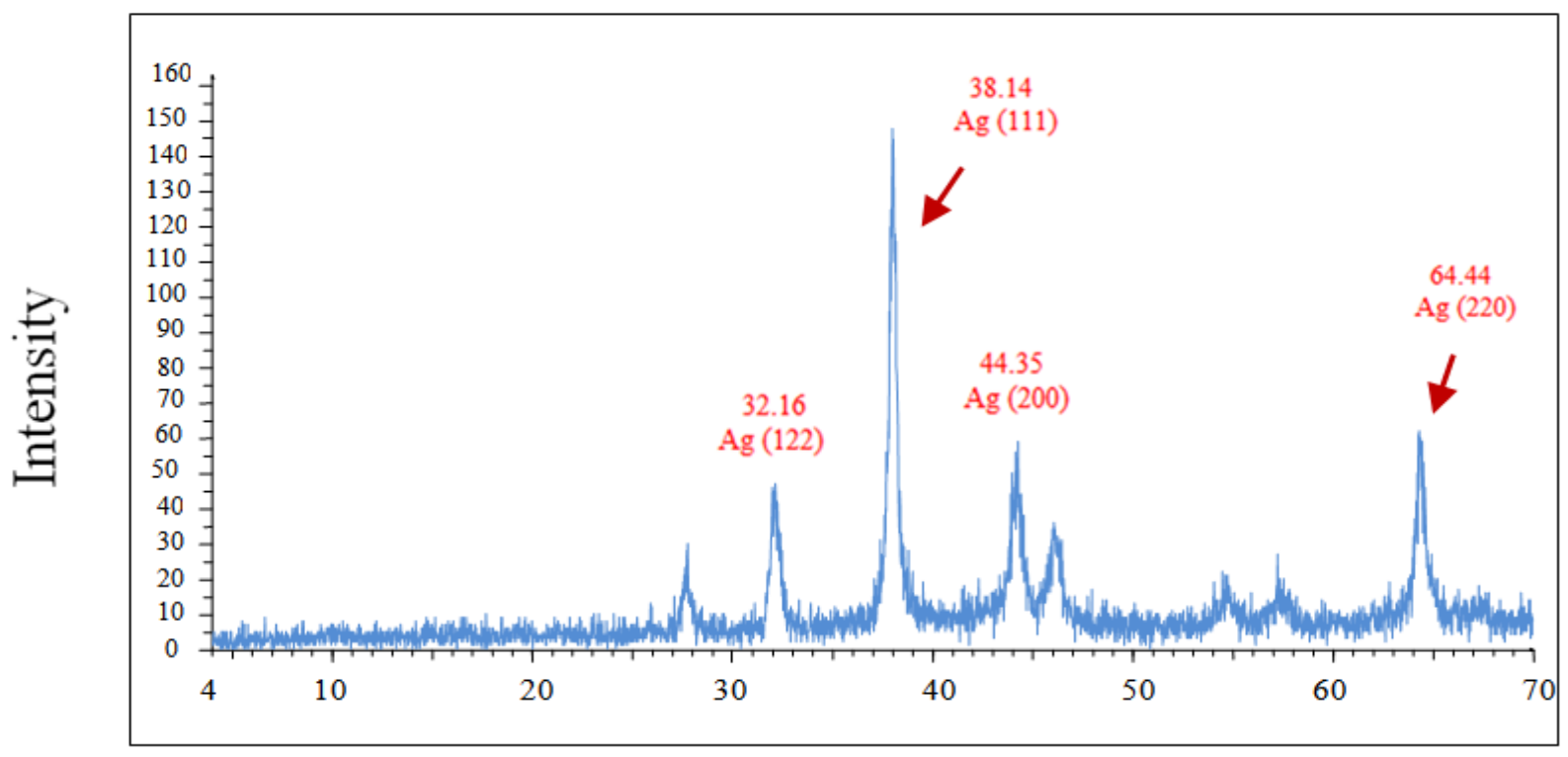

2 Theta / degree

Fig. 2 - X-ray diffraction spectrum of silver nanoparticles synthesized by glucose solution.
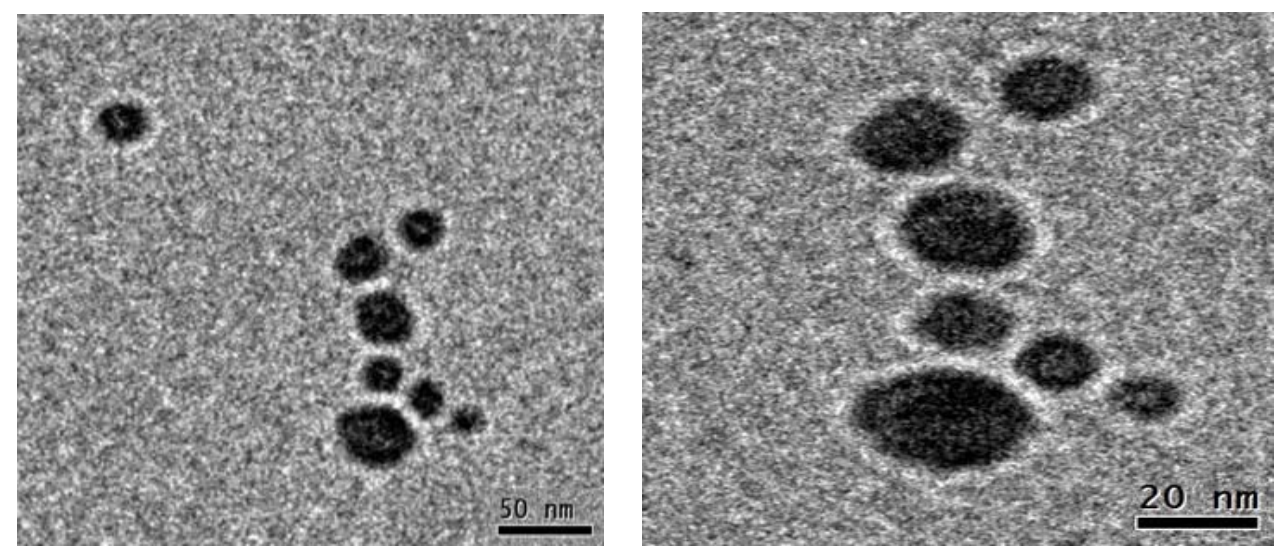

Fig. 3 - TEM images and corresponding size of AgNPs synthesized by glucose solution.

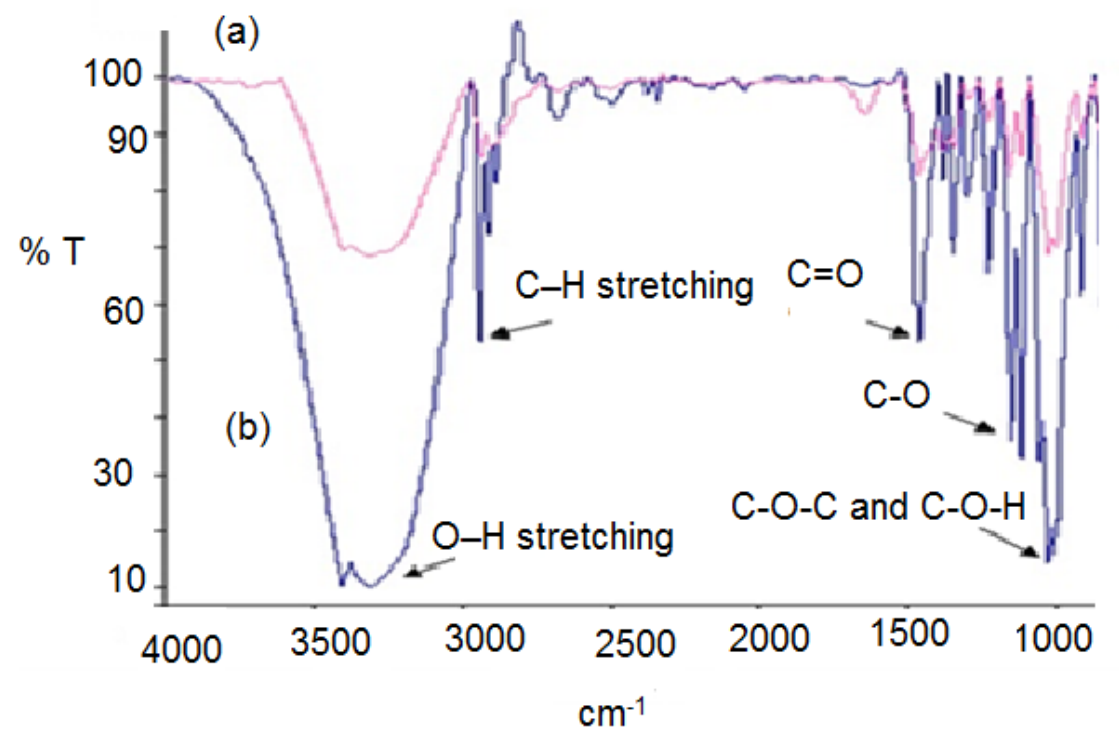

Fig. 4 - FTIR spectra of (a) pure glucose and (b) synthesized Ag-NPs by glucose solution. 


\section{X-ray Diffraction}

Figure 2 illustrates four different diffraction peaks of XRD profile of AgNPs at $2 \theta=32.16^{\circ}$, $38.14^{\circ}, 44.35^{\circ}$, and $64.44^{\circ}$ so can readily be indexed as (122), (111), (200) and (220) planes for face centered cubic structures of silver according to JCPDS card no. 04-0783. Considering the observation of very sharp peaks, the synthesized AgNPs had a crystalline nature. ${ }^{16}$ Other patterns with low intensity can be due to impurities.

The average crystalline size of the silver nanoparticles was estimated using the well-known (Eq.1), the Debye-Scherrer`s equation:

$$
\mathrm{d}=\frac{K \lambda}{\beta \cos \theta}
$$

The average grain crystalline size of AgNPs was estimated to be approximately $8 \mathrm{~nm}$ and about $11 \mathrm{~nm}$.

The average crystalline size of Ag-NPs grains was estimated to be in the range of $8-11 \mathrm{~nm}$.

\section{Transmission Electron Microscopy}

TEM image (Fig. 3) demonstrated that the most AgNPs were obviously spherical in shape and well dispersed, with a mean size of $11.5 \mathrm{~nm}$. Also the morphology of the AgNPs is variable, with majority of them spherical. Under careful observation, we can see that the nanoparticles are not in direct contact even within the aggregates. They are surrounded by a thin organic layer capping the AgNPs, which appears to be characteristic of AgNPs prepared by glucose solution.

\section{FTIR Spectroscopy}

Fourier transform infrared spectroscopy (FTIR) measurements were carried out to identify the possible biomolecules responsible for reduction and efficient stabilization of the silver nanoparticles. In Fig. 4, the FTIR spectra of biosynthesized Ag-NPs and glucose as reducing agent are shown. The absorption bands at 3005$3876 \mathrm{~cm}^{-1}$ are attributed to the $\mathrm{O}-\mathrm{H}$ stretching band, $\sim 2900 \mathrm{~cm}^{-1}$ is related to the aliphatic $\mathrm{C}-\mathrm{H}$ stretching, and also the combination band of $\mathrm{C}-\mathrm{O}-$ $\mathrm{C}$ and $\mathrm{C}-\mathrm{O}-\mathrm{H}$ deformation was noticed form 1526 to $1347 \mathrm{~cm}^{-1}$. In the region from 995 to 1191 , the $\mathrm{C}-\mathrm{O}$ and $\mathrm{C}-\mathrm{C}$ vibration modes are shown and the carbohydrates generally present their characteristic bands. As can be seen in Fig. 4a, the reaction of silver ions with glucose solution can be confirmed by the change in the spectra. The IR band at 1730 is the characteristic of the $\mathrm{C}=\mathrm{O}$ stretching mode of the carboxylic acid group for gluconic acid. ${ }^{17}$ So the bio-reaction of $\beta$-D-glucose with silver ions can be also observed in the region of $1730 \mathrm{~cm}^{-1}$ which is attributed to the binding of $\mathrm{C}-\mathrm{O}$ in carboxylic acid in gluconic acid, and when the peak changed to $1007 \mathrm{~cm}^{-1}$ and lower frequency is good evidence for the reduction of these ions to nanoparticles, as shown in Fig. 4b. This observation is due to the oxidation of hydroxyl groups in D-glucose to carboxylic acid and release of electron which can reduce $\mathrm{Ag}^{+}$ions to $\mathrm{Ag}^{0} \mathrm{NPs}$.

\section{CONCLUSION}

In this study, silver nanoparticles were synthesized by green method using glucose solution, which acted as reducing and capping agent. Analytical techniques such as UV-Vis, XRD, FTIR, SEM and TEM are used to evaluate the AgNPs synthesis by this eco-friendly method. The obtained AgNPs with an average size of $11.5 \mathrm{~nm}$, crystalline and spherical in shape were also reported in this work. Finally, the green synthesis of silver nanoparticles is very simple, cost-effective, efficient, non-toxic and eco-friendly method because of the usage of biomaterial, in comparison to chemical and physical synthesis methods. In addition, it is easy to scale up the production of silver nanoparticles to industrial scale utilizing this method.

Acknowledgements. The authors are thankful to the Islamic Azad University, Shahr-e-Qods branch for their support during this research.

\section{REFERENCES}

1. M. Chung, I. Park, K. Seung-Hyun, M. Thiruvengadam and G. Rajakumar, Nanoscale Res. Lett., 2016, 40, 1-14.

2. R. Meena and N. Chouhan, Research J. Recent Sci., 2015, 4, 47-52.

3. B. Mohapatra, S. Kuriakose and S. Mohapatra, J. Alloys Compounds., 2015, 637, 119-126.

4. N. J. Reddy, D. N. Vali, M. Rani and S. S. Rani, Mater. Sci. Eng. C., 2014, 34, 115-122.

5. M. Jitendra, B. Amla, S. Abhijeet, M. S. Madan, $A d v$. Nat. Sci. Nanosci. Nanotechnol., 2014, 5, 1-10.

6. M. K. Deepa, T. N. K. Suryaprakash, P. Kumar, J. Chem. Pharma. Research., 2016, 8 , 411- 419.

7. S. Ghiassi1, S. Sedaghat, M. Mokhtary and H. Kefayati, J. Nanostruct. Chem., 2018, 8, 353-357. 
8. J. Karimi and S. Mohsenzadeh, J. Med. Sci., 2013, 111, 64-69.

9. K. Anandalakshmi, J. Venugobal and V. Ramasamy, Appl Nanosci., 2016, 6, 399-408.

10. M. Jannathul Firdhouse and P. Lalitha, J. Nanotechnology, 2015, 1-18.

11. S. Sedaghat, A. Esmaeili Agbolag and S. Bagheriyan, J. Nanostruct Chem., 2016, 6, 25-27.

12. C. Pettegrew, Z. Dong, M. Z. Muhi, S. Pease, M. Abdul Mottaleb and M. Rafiq Islam, ISRN Nanotechnology., 2014, 1-9.
13. K. Roy, C. K. Sarkar and C. K. Ghosh, Digest J. Nanomater. Biostructures., 2014, 3, 1137-1147.

14. P. Afshar and S. Sedaghat, Current Nanoscience, 2016, $1,90-93$.

15. K. Shameli, M. Bin Ahmad, D. Jazayeri, S. Sedaghat, P. Shabanzadeh, H. Jahangirian, M. Mahdavi and Y. Abdollahi, Int. J. Mol. Sci., 2012, 13, 6639-6650.

16. Z. Abidin Ali, R. Yahya, S. Devi Sekaran and R. Puteh, Adv. Mater. Sci. Eng., 2016, 1-6.

17. T. Kokila, Ps. Ramesh and D. Geetha, Appl. Nanosci., 2015, 5, 911-920. 
